\title{
Copper(II)-mediated regeneration of carbonyls from oximes and semicarbazones under solvent-free microwave irradiated conditions
}

\author{
Nilay Karchaudhuri, Aparna De and Alok Kumar Mitra* \\ Department of Chemistry, University of Calcutta, 92, Acharya P. C. Road, Kolkata-700 009, India
}

E-mail : akmitra@cucc.ernet.in_Fax:91-033-2351-9755

Manuscript received 21 Jamuary 2003, revised 30 May 2003, accepted 3 July 2003

\begin{abstract}
Carbonyl compounds can be regenerated from the corresponding oximes and semicarbazones by a solvent-free, rapid, efficient and simple method under microwave irradiation exploiting copper(II) chloride.
\end{abstract}

The easy preparation and high stability of oximes and semicarbazones provide the most acceptable methods of protection $^{1}$ of carbonyl compounds to the organic chemists. Oximes and semicarbazones are also extensively used for characterization and purification of carbonyls. So the methods of deprotection ${ }^{2}$ of carbonyls from oximes and semicarbazones are of immense importance. Although quite a number of methods of regeneration of carbonyls are known, the search for newer, efficient and fast methods are going on.

Some of the recent methods reported for deoximation of carbonyls consist of dimethyl dioxirane ${ }^{3}, t$-butylhydroperoxide $^{4}$, ammonium persulphate-silica ${ }^{5}$, manganese triacetate $^{6}, N$-halo amides ${ }^{7}$, sodium periodate-silica ${ }^{8}$, Desmartin periodinane ${ }^{9}$, sodium bismuthate-silica ${ }^{10}$.

Moderate works on regeneration of carbonyls from the corresponding semicarbazones include pyruvic acid ${ }^{11}$, sodium nitrite/glacial acetic acid ${ }^{12}$, mercury(II) acetate, thallium(II) acetate, lead(IV) acetate ${ }^{13}$, clayfen ${ }^{14}$, nitrous $\operatorname{acid}^{15}$, Dowex-50 $0^{16}$, Amberlyst 15/aq. acetone ${ }^{17}$, tetrakis(pyridine) silver dichromate/benzene ${ }^{18}$, copper chloride/ $\mathrm{CH}_{3} \mathrm{CN}^{19}$, sodium bismuthate/silica ${ }^{20}$, antimony trichloride $^{21}$ etc. The method using copper chloride in $\mathrm{CH}_{3} \mathrm{CN}$ suffers from several disadvantages involving the refluxing condition with longer reaction time (10-390 $\mathrm{min})$, very poor yield for particular compound ( $7 \%$ for $p$-nitrobenzaldehyde) and the use of organic solvent $\left(\mathrm{CH}_{3} \mathrm{CN}\right)$ which generates the problem of solvent-waste. So our attempt was to search for a faster, simple and solvent-free reaction condition.

Recently, the emerging trend of wide application of microwave radiation in chemical reaction enhancement ${ }^{22}$ is due to high reaction rates with the minimization of side reactions resulting cleaner products and the operational simplicity. The current approach involves the use of inorganic reagents in solvent-free condition ${ }^{23}$ as these reactions often involve the milder reaction, easier work-up and higher selectivity than similar reactions using organic reagents in solution. In continuation of our attempt ${ }^{24}$ in this field, herein we wish to report a solid state deprotection of carbonyls from oximes and semicarbazones exploiting $\mathrm{Cu}^{\mathrm{Il}}$ chloride under microwave irradiation (Scheme 1).

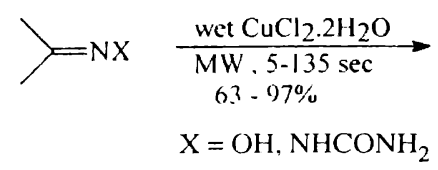

Scheme 1

The carbonyls are regenerated in high yields (63-97\%) at ambient pressure within 5-135 s (Table $\mathrm{I}$ and Table 2).

Table 1. Microwave assisted deoximation using cupric chloride dihydrate

\begin{tabular}{clcc} 
Entry & Oxime of & Time & Yield \\
& & $\mathrm{s}$ & $\%$ \\
1 & Benzaldehyde & 24 & 92 \\
2 & Anisaldehyde & 23 & 92 \\
3 & 3-Nitrobenzaldehyde & 30 & 74 \\
4 & 4-Nitrobenzaldehyde & 57 & 71 \\
5 & Vanillin & 22 & 85 \\
6 & Isovanillin & 74 & 73 \\
7 & Veratraldehyde & 34 & 78 \\
8 & Piperonal & 48 & 90 \\
9 & O-Benzylvanillin & 32 & 84 \\
10 & O-Benzylisovanillin & 51 & 79 \\
11 & Acetophenone & 20 & 81 \\
12 & 4-Methoxyacetophenone & 75 & 74 \\
13 & 4-Methylacetophenone & 18 & 78 \\
14 & 4-Nitroacetophenone & 135 & 73 \\
15 & Benzophenone & 17 & 91 \\
16 & Cyciohexanone & 7 & 88 \\
17 & Isobutyl methyl ketone & 48 & 63 \\
\hline
\end{tabular}




\begin{tabular}{clcc}
\hline \multicolumn{4}{c}{ Table 2. Microwave assisted regeneration of carbonyls from } \\
Entry & Semicarbazones using cupric chloride dihydrate \\
& & Time & Yield \\
1 & Benzaldehyde & s & $\%$ \\
2 & Anisaldehyde & 51 & 93 \\
3 & 3-Nitrobenzaldehyde & 45 & 92 \\
4 & 4-Nitrobenzaldehyde & 26 & 75 \\
5 & Vanillin & 30 & 70 \\
6 & Isovanillin & 12 & 93 \\
7 & Veratraldehyde & 74 & 71 \\
8 & Piperonal & 19 & 85 \\
9 & O-Benzylvanillin & 50 & 86 \\
10 & O-Benzylisovanillin & 57 & 89 \\
11 & Acetophenone & 34 & 91 \\
12 & 4-Methylacetophenone & 7 & 97 \\
13 & 4-Methoxyacetophenone & 6 & 96 \\
14 & 4-Nitroacetophenone & 10 & 95 \\
15 & 2-Naphthyl methyl ketone & 35 & 88 \\
16 & Cyclohexanone & 5 & 68 \\
17 & 7-Methoxytetralone & 28 & 92 \\
18 & Isobutyl methyl ketone & 20 & 71 \\
\hline
\end{tabular}

The optimum ratio of the substrate to reagent is found to be $1: 1(\mathrm{~mol} / \mathrm{mol})$. The lower amount of the reagent results incomplete reaction. The dry reagent decomposes under microwave irradiation. So the reagent is moistened, as water is highly microwave active, resulting the efficient absorption of heat. By conventional heating method (oilbath) at $110^{\circ}$ in the presence of the reagent, the reaction was still incomplete after $22 \mathrm{~h}$. The reagent has wide applicability for regeneration of both aldehydes and ketones from oximes and semicarbazones whereas many of the already reported methods cannot regenerate aldehydes from the corresponding oximes and semicarbazones. The plausible mechanism for $\mathrm{Cu}^{\mathrm{ll}}$ mediated regeneration of carbonyls is stated below :

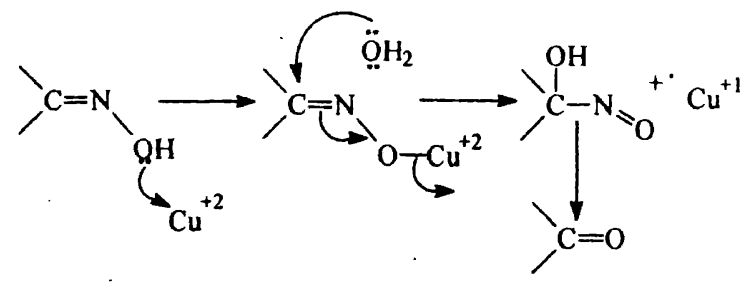

\section{Experimental}

IR spectra were recorded on a Perkin-Elmer FT-IR-RXI spectrophotometer. ${ }^{1} \mathrm{H}$ NMR spectra were recorded on
Bruker AM 300L spectrometer operating at $300 \mathrm{MHz}$. The reactions were carried out in a domestic microwave oven (BPL, 800T/MM $261 \mathrm{EEP}$ ).

General procedure: A mixture of oxime/semicarbazone (1 mmol), $\mathrm{CuCl}_{2} \cdot 2 \mathrm{H}_{2} \mathrm{O}(1 \mathrm{mmol})$ and water $(0.5 \mathrm{ml})$ was taken in a $25 \mathrm{ml}$ Erlenmeyer flask placed in an aluminabath (heat-sink) inside a domestic microwave oven and irradiated for the specified time at power level of $700 \mathrm{~W}$ and the reaction was monitored by TLC. The product was extracted with ethyl acetate $(2 \times 5 \mathrm{ml})$, washed with brine $(5$ $\mathrm{ml}$ ) and dried over sodium sulphate. Evaporation of the solvent afforded the product in high yield.

In conclusion, we have developed as solvent-free rapid method for the facile cleavage of carbon-nitrogen bond in oximes and semicarbazones under microwave irradiation to regenerate carbonyls.

\section{Acknowledgement}

The authors are grateful to the C.S.I.R., the U.G.C., New Delhi and University of Calcutta for providing the financial support for this work.

\section{References}

1. A. I. Vogel, "Textbook of Practical Organic Chemistry", 4th. ed., ELBS and Longman, London, 1978, p. 1112.

2. T. W. Greene i...d P. G. M. Wuts, "Protective Groups in Organic Synthesis", 2nd. ed., Wiley, New York, 1991, p. 214.

3. G. A. Olah, Q. Liao, C. S. Lee and G. K. Surya Prakash, Synlett, 1993, 427.

4. N. B. Barhate, A. S. Gajare, R. D. Wakharkar and A. Sudalai, Tetrahedron Lett., 1997, 38, 653.

5. R. S. Varma and H. M. Meshram, Tetrahedron Lett., 1997, 38, 5427.

6. A. S. Demir, C. Tanyeli and E. Altinel, Tetrahedron Lett., 1997, $38,7267$.

7. B. P. Bandgar, L. B. Kunde and J. L. Thote, Synth. Commun., 1997, 27, 1149.

8. R. S. Varma, R. Dahiya and R. K. Saini, Tetrahedron Lett., 1997, 38,8819 .

9. S. S. Chaudhuri and K. G. Akamanchi, Tetrahedron Lett., 1998, 39, 3209 .

10. A. K. Mitra, A. De. and N. Karchaudhuri, Synlett, 1998, 1345.

11. E. B. Hershberg, J. Org. Chem., 1948, 13, 542.

12. S. Goldschmidt and W. L. C. Veer, Recl. Trav. Chim. PyasBas, 1946, 65, 796.

13. R. N. Butler, G. J. Morris and A. M. O'Donohue, J. Chem. Res. (S), 1981, 61 .

14. P. Laszlo and E. Polla, Synthesis, 1985, 439. 
15. A. Castello, C. Jaime, J. Marquet and M. Moreno-Manas. Tetrahedron, 1985, 41, 3791.

16. B. C. Ranu and D. C. Sarkar, J. Org. Chem., 1988, 53, 878,

17. R. Ballini and M. Petrini, J. Chem. Soc., Perkın Trans. I, 1988, 2563.

18. H. Firouzabadi, M. Seddighı, Z. A. Ahmadi and A. R. Sardarian, Synth. Commun., 1989, 19, 3385.

19. R. N. Ram and K. Varsha, Tetrahedron Lett., 1991, 32, 5829.

20. A. K. Mitra, A. De. and N. Karchaudhuri, J. Chem. Res. (S), 1999, 320.

21. A. K. Mitra, A. De. and N. Karchaudhuri, Synth. Commun., 2000, 30, 1651.

22. S. Caddick, Tetrahedron, 1995, 51, 10403; S. A. Galema, Chem. Soc. Rev.; 1997, 26, 233; F. Langa, P. D. L. Cruz, A. D. L. Hoz, A. Diaz-Ortiz and E. Diez-Barra, Contemp. Org. Synth., 1997, 4, 373; A. K. Bose, B. K. Banik, N. Lavlınskaia, M. Jayaraman and M. S. Manhas, Chemtech,
1997, 27, 18; R. S. Varma, Green Chem., 1999, 43; N.-F. K. Kaiser, U. Bremberg, M. Larhead, C. Moberg and A. Hallberg, Angew. Chem. Int. Ed. Engl., 2000, 39. 3596; B. Desai and T. N. Danks, Tetrahedron Lett., 2001, 42, 5963; J. C. Lee and J. H. Choi, Synlett, 2001. 234: B. M Barchin, A. M. Cuadro and J. A. Buslla, Synlett, 2002, 343; R. N. de Olıversa, J. R. de F. Filho and R. M. Srivastava, Tetrahedron Lett., 2002, 43, 2141.

23. A. Oussaid, L. N. Thach and A. Loupy, Tetrahedron Lett., 1997, 38, 2451; R. S. Varma, R. Dahıya and R K Sainı, Tetrahedron Lett., 1997, 38, 7029; J. M. Lerestıf, L. Toupet, S. Sımbandhit, F. Tonnard, J. P. Bazureau and J. Hamelın, Tetrahedron, 1997, 53, 6351; B. C. Ranu, S. K. Guchhait, K. Ghosh and A. Patra, Green C/eem., 2000, 5.

24. A. K. Mitra, A. De and N. Karchaudhuri, Synth. Commun., 1999, 29, 573: J. Chem. Res. (S), 1999, 246, 560; Synth. Commun., 1999, 29. 2731; Indian J. Chem.. Sect. B, 2000, 39, 387; J. Indian Chem. Soc., 2001, 78, 721; J. Chem. Res. (S), 2002, 180. 